\title{
Fault diagnosis and maintenance of automobile engine cooling system
}

\author{
Chunmei Chen \\ Shandong Transport Vocational College, Weifang, Shandong 261206, China; 462204159@qq.com
}

\begin{abstract}
With the further development of the society, the economic level of Chinese residents is gradually improving. Under such circumstances, the number of automobiles and their usage are increasing as well. As a kind of mechanical equipment, there will be many application faults of the automobile after long-term use. Only by solving the faults can automobiles be restarted and run stably for a long time. Based on this, this paper focuses on automobile maintenance, analyzes the principle of engine cooling system, and studies the diagnosis and maintenance methods of this kind of fault, trying to provide some reference value for the further discussion and research in this field.
\end{abstract}

Keywords: Automobile maintenance; engines; cooling system; fault diagnosis

\section{Introduction}

The existence of cooling system is very necessary and important to the automobile engine, whose function is to enable the automobile to run for a long time with a perfect performance of the engine. The cooling method is water pump and cooling water. When the automobile engine works, the cooling water continues to cycle under the action of the water pump, thus taking away the heat generated by the engine and keeping it at a basic constant temperature. In addition, the auxiliary radiator in the system can reduce the heat of the engine by exchanging heat energy. However, with the increase of application times, many faults will occur in the cooling system. At this time, it is necessary to combine the causes of the faults and carry out targeted treatment in order to ensure the normal operation of the automobile. Therefore, the research on fault diagnosis and maintenance of automobile engine cooling system is of great practical significance.

\section{Working principle of the cooling system}

The cooling system of modern automobile engines mainly includes two modes, namely water cooling and air cooling, and most of the water cooling systems adopt closed circulating modes. From the perspective of the composition structure, there are cooling fan, compensation water tank and thermostat in the cooling system besides water pump and radiator.

During the process, the water pump will accelerate the circulation speed of the cooling water; then the natural wind generated by operation of the automobile and the fan will cool the cooling water, which will enter the water jacket for standby. In this way, the cycle can be repeated to ensure the continuous cooling of the engine. There are many operation ways of the cooling system. The selection of the way to operate will depend on the engine temperature. For example, when the engine temperature is low, the cooling water will circulate in the engine without passing through the radiator and take away the engine heat quickly, which is called the small circulation of the automobile cooling system. When the temperature of cooling water exceeds 80 degrees, small circulation cannot be carried out because the thermostat will be actively closed. Large circulation will occur at this stage, that is after entering the engine, cooling water will enter the

Copyright (C) 2020 Chunmei Chen

doi: $10.18063 /$ vd.v4i1.1151

This is an open-access article distributed under the terms of the Creative Commons Attribution Non-Commercial License

(http://creativecommons.org/licenses/by-nc/4.0/), which permits non-commercial use, distribution, and reproduction in any medium, provided the original work is properly cited. 
radiator to dissipate heat and then enter the water jacket for standby.

The engine cooling system can be divided into two forms, namely natural air cooling and forced air cooling. The former is to cool the engine by applying natural air, in which the cylinder body and head of the automobile are connected to each other, and materials with good thermal conductivity is used to help dissipate heat. The latter relies on the own fan of the engine to dissipate heat, ensuring that the airflow on the surface of the heat sink is large and fast enough, which is the most widely adopted and effective method at present.

\section{Fault diagnosis and maintenance analysis of automobile engine cooling system}

\subsection{High cooling water temperature}

When the cooling water temperature is too high, the water thermometer will exceed the warning red line to reflect it, and there will be no recovery for a long period of time, finally causing the cooling water in the water tank to boil. At this time, the engine cooling system is abnormal, which needs to be checked immediately. Common causes of the above problems include the following types: the cooling pump is damaged or blocked; The amount of cooling water is insufficient during circulation; the system radiator may be blocked due to some reasons like precipitation; there is something wrong with the thermostat.

(1) If the temperature of cooling water rises rapidly after the engine starts, there is a great possibility that there is a problem with the internal thermostat, which should be replaced in time. (2) If pollution and deformation are found on the radiator during maintenance, it should be cleaned and replaced. (3) If the temperature of cooling water has not dropped or there is no reflux, it is quite likely that the cooling pump is blocked and should be replaced in time. (4) If the cooling water level is found to be low, the amount of cooling water in the system may be insufficient, and then it should be added.

\subsection{Leakage of cooling water}

If there are water traces on the ground and white smoke in the exhaust pipe when the automobile is running, it is obvious that cooling water in the engine cooling system is leaking, resulting in insufficient cooling water volume and failure to complete the cooling task. Leakage can be divided into two types, one is internal leakage and the other is external leakage. The former is difficult to be found and usually requires careful investigation. The latter is more obvious as cooling water directly leaks onto the ground.

In case of this kind of situation, (1) the leakage part needs to be carefully checked. If leakage occurs in the cylinder gasket or the radiator, they have to be repaired or replaced; (2) poor sealing performance of the engine itself can also lead to leakage of cooling water. For example, cylinder body or head with cracks and deformation caused by external force need to be repaired in time; (3) if the joint of the cooling system is blocked by a large amount of scale or rust in the water pipe, it needs to be dredged or replaced in time.

\subsection{Low cooling water temperature}

When the power of the engine continues to decrease while the automobile is running, and the water temperature is below $75^{\circ} \mathrm{C}$, accompanied by the explosion sound in the exhaust pipe, and increase of the oil consumption, the problem is that the cooling water temperature is too low.

(1) After starting the automobile, the maintenance personnel will immediately open the water tank cover and accelerate the running speed of the engine. If the water flow in the engine is large and fast, it is proved that the thermostat is not installed or the valve is stuck which requires installment or replacement. (2) If the radiator is hot and the water temperature is normal, it indicates that there is a fault in the thermometer or temperature sensor. Then, they should be repaired or replaced if necessary. 


\section{Maintenance of cooling system}

\subsection{Selection of cooling water}

The choice of cooling water has always been ignored by automobile users, but its influence on the cooling system is very obvious. It is suggested that water with lower hardness, such as well water, should be selected and boiled to be softened. In winter, antifreeze should be added to the cooling water.

\subsection{Maintenance of cooling water}

Special attention should be paid to the replacement of cooling water for maintenance. As the cooling water is usually of certain toxicity, care must be taken during the replacement to ensure safety. Secondly, it is necessary to check the liquid height of the cooling water in the water tank. If the radiator and the cylinder gasket need to be replaced during the maintenance of the automobile, the cooling water must be replaced correspondingly. All replacement activities need to be carried out after the engine is completely cooled.

\subsection{Cleaning and maintenance of cooling system}

The cleaning process is: starting the automobile engine first, then stopping it to add cleaning solution; secondly, stopping the engine after restarting it for a period of time and removing the cleaning solution. This cycle continues until the removed cleaning solution is clean.

What should be noted is: start-up time of the engine should be 10 to 15 minutes; if the engine temperature is lower than $85^{\circ} \mathrm{C}$, the throttle valve cannot be opened, and only small cycle can be carried out at this time.

\subsection{Detection and maintenance of water pump belt}

The pump belt is a whole mechanical system with fans and engines. Generally speaking, the belt material applied is rubber. Although this material has good toughness and ductility, there will by aging problems after applied for a long time. In order to solve this problem, the strength of the rubber inner core can be further improved, or regularly inspected to avoid problems in advance.

\section{Conclusion}

To sum up, the cooling system of the automobile engine, as an important component of the automobile, plays an important role in the operation of the automobile. With the increase of the number of automobiles used, the fault of the cooling system is inevitable. Therefore, targeted treatment should be carried out according to the type of fault to avoid damage to the overall performance of the automobile. At the same time, the automobile should be well maintained in daily use, which can effectively reduce the probability of fault and improve the service life of the internal system in the automobile.

\section{References}

1. Chen C, Tian Z, Wang G, et al. Hardware design of intelligent monitoring system for automobile engine cooling water (in Chinese). Automobile Applied Technology 2019; (24): 133-134. doi: 10.16638/j.cnki.1671-7988.2019.24.043.

2. Li F, Shi P, Yu J. Study on the influence of cooling fan of automobile engine on thermal management of the Engine Compartment (in Chinese). Automobile Applied Technology 2019; (14): 95-98.

3. Wang H, Zhu H, Hua Q, Xu K. Development of adaptive and self-diagnosis controller for the engine electronic cooling pump. Machine Design and Maunufacturing Engineering 2019; 48(2): 29-32. doi: 10.3969/j.issn.2095-509X.2019.02.008.

4. Zhang W. Key techniques research of fault diagnosis and maintenance for vehicle engine cooling system. Automobile Parts 2017; (3): 74-77. doi: 10.19466/j.cnki.1674-1986.2017.03.019.

5. Zhang W. Research on fault diagnosis and maintenance technology of engine cooling system of large mining truck with electric wheels. Energy Saving of Non-ferrous Metallurgy 2016; 32(6): 38-42. doi: $10.3969 /$ j.issn.1008-5122.2016.06.009. 
6. Wang M. Discussion on fault diagnosis and maintenance of automobile engine cooling system (in Chinese). Hubei Nongjihua 2020; 42(1): 84.

7. Liu M. Analysis on the faults of automobile engine cooling system and the maintenance (in Chinese). Auto Time 2019; 17(6): 158-159.

8. Niu Y. Fault diagnosis and maintenance of automobile engine cooling system (in Chinese). Automobile Maintenance 2018; 26(11): 9-10. doi: 10.3969/j.issn.1009-2625.2018.11.004. 